\title{
Investigation of the Evaluation Techniques in Early Childhood Education: A Comparative Research in the Greek School
}

\author{
Maria Sakellariou ${ }^{1}$, Polyxeni Mitsi ${ }^{1} \&$ Panagiota Strati ${ }^{1}$ \\ ${ }^{1}$ Department of Pre-School Education, University of Ioannina, Greece \\ Correspondence: Polyxeni Mitsi, PhD Candidate, M.Ed., Department of Pre-School Education, University of Ioannina, \\ Greece. E-mail: pollymitsi@yahoo.gr
}

Received: December 17, 2019

Accepted: December 29, 2019

Online Published: December 31, 2019

doi:10.5430/irhe.v4n4p29

URL: https://doi.org/10.5430/irhe.v4n4p29

\begin{abstract}
The evaluation of the pedagogical process in early childhood care and education is an up-to-date and controversial subject of study in the context of scientific and policy choices and actions (Charisis, 2006; Doliopoulou \& Gourgiotou, 2008; McAfee, Leong, Bodrova, 2010). The purpose of this paper is to investigate the evaluation techniques applied in preschool education by the teachers and prospective teachers in kindergartens, who are also the sample of our research, in the region of Epirus and at the University of Ioannina. In our research we used the structured questionnaire with closed and some clarifying open-ended questions. The data of the research highlighted the prospective teachers' more positive attitude to apply alternative evaluation techniques to kindergarten but ultimately the difficulty in their practical implementation. Despite the limitations of the research, the data is the trigger for further exploration of the subject of teacher education and the reform of the curriculum in the pedagogical departments of Preschool Education of the Greek Universities in order to divest the kindergarten from the promotional character and the authentic evaluation to ensure the children's development by themselves.
\end{abstract}

Keywords: evaluation techniques, early childhood education, teachers, prospective teachers

\section{Introduction}

In the era of post-modernism, assessment during the pre-school age, undoubtedly constitutes one of the most contentious issues within the educational reality, even if in Greek reality, the orientation of assessment on the field of preschool education emphasizes on the process itself, promoting the elaborative aspect of the evaluation rather than the final outcome. However, via the official educational policies along with the existing guidelines offered to the Kindergarten Educators, formative assessment sadly is not given its due importance, although it serves as a guarantee for the implementation of appropriate curricula regarding pre- school education and learning (McAfee Leong, Bodrova, 2010).

The evaluation of a child within the school environment is manifested as a multi-leveled as well as multi-emphatic phenomenon, having theoretical, practical, pedagogical, scientific, political, personal and ethical dimensions. Therefore, the mode of organizing and operating the assessment makes up a social stake reaching out personal but also, practical extends (Constantinou \& Constantinou, 2017). By the term of "assessment" one means the "process of collecting information regarding children, all of which stem out of a range of elements, thereafter organizing and interpreting of these information" (McAfee, Leong, Bodrova, 2010).

In our country, the policies towards pre-school assessment were, for several years, adapted on the norms of the Elementary School which introduced a traditional context of techniques, methods and means of evaluation, on the service of declaratory as well as monitoring purposes. This was due to the absence of theoretical contextualization but also practical implementation (Doliopoulou, \& Gourgiotou, 2008. Puckett \& Diffily, 2003). However, it seems, that alternative or authentic assessment techniques are capable of fructifying more analytically and more profoundly the real picture of the child, through anthropological characteristics on an ideological basis as well as on the basis of an equal sociological approach (Gullo, 2005. Wortham, 2015. Bagnato, 2009).

Assessment of toddlers exhibits significant challenges which affect and hold back the selection of proper evaluation techniques, given the rapid developmental changes which necessitate the acknowledgement of psychological, corporal and social evolution of the child (Gullo, 2005). Furthermore it is scientifically ascertained that kindergarten teachers 
find difficulties when carrying out the assessment of not only pupils but of the educational process itself, since their expertise on evaluation issues is quite limited (Doliopoulou, 2008). It is, therefore crucial that a theoretical context is well established, based on the assessment process as this is manifested in the existing literature, and a syncretism of traditional and alternative assessment techniques for pupils should be sought, in order for the evaluation procedure to fully accomplish its pedagogical mission (Christoforidou, Kyriakides, Antoniou, \& Creemers, 2014). It is critical, so to speak, that professional growth- oriented programs are implemented, which shall be of intensive character, continuously linked to practicum and focus on specific academic content, respective to the educators' needs and requests (Linda- Darling Hammond, 2015).

The researches in both Greek and foreign literature demonstrate the importance of kindergarten in the development of students' competences and skills in various fields (Eurydice, 2004). The most modern theories of learning contest traditional perceptions of assessment and propose alternative forms that focus on the overall development of the pupil and the improvement of the educational process. In our country, the first references for alternative assessment techniques in preschool education took place with the establishment of the current Interdisciplinary Unified Curriculum Framework for Kindergarten (Pedagogical Institute, 2013), in which is the advantages of alternative assessment are highlighted in contrast to the traditional. In the Greek educational system, the implementation of an alternative assessment system, in addition to the traditional assessment system, where student progress will not be assessed using only marks, remains a trigger for further investigation. At the same time, there have been significant efforts in the field of scientific papers, books, articles and researches on student assessment and teachers' views on this subject. However, no such effort so far has examined the feasibility of alternative techniques in kindergarten fact that makes it worth studying. In addition, the findings of the present research can be a subject of concern and an important source of information for kindergarten teachers. Moreover, the results can lead to the necessary improvements and contribute to a more appropriate design of assessment techniques in kindergarten, with the ultimate aim of improving and developing learning. It is also worth noting that teachers are given the opportunity to clarify their expectations, share their concerns and objections to the implementation of alternative assessment techniques in kindergarten.

\section{Methodology of the Research}

\subsection{Purpose of the Research}

The following investigational approach attempts to explore and compare the assessment techniques that are implemented on pre-school education by educators as well as hopeful educators of pre- school aged children. In particular, our purpose is to explore which assessment techniques are used by teachers in Greek kindergartens and to compare them with the techniques used by the prospective teachers. It is interesting to investigate the theoretical knowledge of our sample on the assessment techniques in Greek kindergartens and if or how often implement them practically in everyday school life. Also, we examine the Knowledge and the practical implementation of alternative assessment techniques by the teachers and prospective teachers in kindergartens. We try to understand if the teachers and prospective teachers believe that assessment is useful or necessity in kindergarten and for which reasons. Furthermore, we examine the time and the frequency of assessment techniques in Greek kindergartens. Finally, we investigate how willing is our sample for further retraining and reeducation on issues concerning evaluation techniques in pre-school education.

\subsection{Sample of the Research}

The specimen of the present study consists of pre- school educators who serve on elementary schools of the District of Epirus, specifically of the Prefectures of Arta, Thesprotia, Ioannina and Preveza, as well as of hopeful pre- school educators who are currently students at the University of Ioannina. The sample consists of 218 individuals in total, specifically 117 kindergarten teachers and 101 students from the Department of Early Childhood Education of the University of Ioannina.

\subsection{Time of Conduction of the Research}

The survey was carried out during the current school year 2018-19, commencing on December 2018 until March 2019.

\subsection{Method of Collecting and Analyzing Data}

For the needs of the present research, an inventory was designed anew, it was structured on the basis of four (4) parts which included "closed" type along with some explanatory "open" type questions. The duration of filling the itinerary would not exceed 15 minutes. The statistical processing was carried out with the use of the SPSS v25.0 for Windows software. The level of statistical materiality was determined to a value of $\mathrm{p}<0,05$. The statistical analysis of data took place through the implementation of Descriptive Statistics-Correlations and Crosstabulations analysis. 


\subsection{Restrictions on the Research}

On the case of the current study a main inhibition factor was the fact that the specimen was restricted only within the four aforementioned regions and only one State University of Greece.

\section{Result Analysis and Interpretation}

\subsection{Demographics}

With regards to the sample's profile, it is established that a mere 5,6\% of the students are of male gender, as opposed to $94,4 \%$ of females. Respectively, within the kindergarten teachers, females outnumber their male colleagues by an overwhelming $96,2 \%$ to $3,8 \%$. The majority of the teachers $(38,4) \%$ belong to the age range between $41-50$ years old, are permanents $(71,4 \%)$ serving on state $(90,8 \%)$ kindergartens while a $48,1 \%$ of total have an employment experience spanning from 21 to 30 years. An 18, $4 \%$ of the kindergarten teachers have completed their post-graduate studies whereas $7 \%$ possess a second degree. Of the total of students 14, 7\% possess an additional diploma. The geographical location of the kindergarten facilities where the students carried out their internship was rural regarding $49,2 \%$ of them, while $62,2 \%$ of the kindergarten teachers work in city schools, $19,5 \%$ in urban areas and an 18,4\% work in semi- urban regions.

\subsection{Necessity and Purpose of Assessment}

On the question regarding the necessity of the assessment within the Kindergarten, the majority of the future kindergarten teachers, responded extremely high at a $44,2 \%$, while a $53,5 \%$ of the kindergarten teachers responded very high. The future kindergarten teachers consider themselves as being highly 58,3\% knowledgeable on toddler evaluation issues, while a 75,1\% of the kindergarten teachers responded lowly knowledgeable, while not more than a $21,6 \%$ responded quite knowledgeable. Prioritizing the elements that should be mainly taken on account during toddlers' assessment for respectively the teachers and the university students the following findings occur; Behaviour (55,1\% to 48,3\%), Capacities and Incapacities of the children (51,4\% to 46,9\%) and for the teachers Sociality (38,9\%) as well Age $(38,9 \%)$ was a third option, while for the future educators the third option was Interests $(42,2 \%)$. Regarding the prioritization relevant to the purpose of the toddlers' assessment, the majority of the specimen subjects responded as following: The progress of the children is indeed manifested $(64,3 \%)$.

\subsection{Implementation of the Assessment}

Of the sample group, the Kindergarten teachers by majority $(63,2 \%)$ carry out the assessment at the end of the organized activities, while most of the intern students $(52,4 \%)$ implemented the assessment prior to, during as well as at the end of organized, freestyle, and daily routine activities. The participating educators by majority carry out the assessment on the following cognitive domains: Linguistics and Mathematics (100\%), Personal and Social Development (94, 5\%), Gymnastics (5, 6\%), Art (11, 3\%), Information and Communication Technologies (ICT) (6, $3 \%$ ), Environmental and Sustainable Development Education (3, 2\%) and Natural Sciences (42\%). A 63, 2\% of the students faced difficulties of some sort, during their internship in the Kindergarten whereas a 55, 3\% of the teachers stated that did not. The percentage of the educators' sample (36,8\% and $44,7 \%$ respectively) who stated that they met some kind of difficulty during the assessment, reported the lack of enough time to conduct it $(46,8 \%)$, the large number of pupils in each kindergarten class (42\%) as well as the scarcity of logistics and sufficient infrastructure (9,52\%). Correlating the location of the kindergarten facilities to the frequency of implementing alternative evaluation techniques, a statistical materiality of $\mathrm{p}=0,038$ was found. More specifically, it was observed that in kindergartens of rural regions, alternative evaluation techniques are rarely implemented.

\subsection{Methods of Evaluating Toddlers and the Means of Surveying the Evaluative Result}

The majority of educators comprising the specimen make an extensive use of the following techniques towards their assessment of toddlers: 
Table 1. Use of assessment techniques

\begin{tabular}{lcc}
\hline \multicolumn{1}{c}{ Techniques of Assessment } & Kindergarten teachers & $\begin{array}{c}\text { Future Kindergarten } \\
\text { teachers (Students) }\end{array}$ \\
\hline Observation & $68,4 \%$ & $65,5 \%$ \\
\hline Folder for team work & $57,1 \%$ & $60,6 \%$ \\
\hline Assign work at the end of each activity & $59,1 \%$ & $62,4 \%$ \\
\hline Daily oral communication with pupils & $69,3 \%$ & $66,4 \%$ \\
\hline Rubric & $3,4 \%$ & $7,3 \%$ \\
\hline Pupil's Portfolio & $13,5 \%$ & $5,4 \%$ \\
\hline Systematic observation & $2,8 \%$ & $7,5 \%$ \\
\hline Self-assessment & $11,3 \%$ & $19,3 \%$ \\
\hline Evaluating others & $9 \%$ & $12,7 \%$ \\
\hline Project & $26,7 \%$ & $27,4 \%$ \\
\hline Pedagogical calendar & $53,4 \%$ & $26,5 \%$
\end{tabular}

From the correlation of the studies level element concerning the educators with the selection of alternative assessment techniques, a materiality value of $\mathrm{p}=0,044$ was established. According to this finding it is determined that educators who possess post-graduate titles make a broader use of alternative assessment techniques during their daily educational act. The investigation on the reasons kindergarten teachers use only limitedly -if any whatsoever- alternative assessment techniques for toddlers, most of them stated that they lack the sufficient degree of knowledge to do so (85, $9 \%$ ), while the students answered that although they are theoretically familiar with those techniques, they actually faced difficulties on their practical implementation $(88,3 \%)$. Moreover, it was recorded that educators holding a post-graduate diploma or additional studies' degree, this being depicted by a materiality value of $\mathrm{p}=0,0478$, reported limited time $(96,7 \%)$ along with the large number of pupils per class $(93,2 \%)$ as being the main reasons of their noncontinuous implementation of alternative assessment techniques. Kindergarten teachers stated that their basic source of updating their knowledge on alternative assessment techniques is the attendance of seminaries, meetings or retraining programmes $(52,4 \%)$, while students mentioned their studies and the knowledge they are provided with, via their university courses $(63,7 \%)$. Finally, a $94,6 \%$ of the kindergarten teachers affirmatively responded to the question whether they wish to be re-educated on subjects of toddler assessment, and stated that their primary desire is that such a project would be actualized through a well- organized systematic retraining, institutionalized by Special Centers $(71,2 \%)$ whereas their second choice would be through seminaries held by experts (e.g. academicians) on pre-school evaluation issues $(52,7 \%)$.

\section{Discussion}

Investigating on the assessment techniques that are implemented within pre-school education by both pre-school educators as well as future pre- school educators formed the kingpin of the present study.

Therefore, as a key finding, the positive view of the current and prospective pre-school educators towards the necessity of implementing assessment within the kindergarten is recorded. Assessment is essential to the educational process and poses a sheer necessity of it being implemented in the kindergarten, since its feedback contribution comes of major importance not only to the pupil but to the teacher as well, while it has a most positive impact on the enhancement and improvement of the educational quality (McAfee Leong, Bodrova, 2010). The conclusions of the present study point out the inadequate reeducation of the pre-school teachers regarding alternative assessment techniques while by means of research, the incapacity of them towards extricating themselves from obsolete teaching and evaluating methods, is clearly revealed (Irving, Harris, \& Peterson, 2011). Carrying out of assessment by the educators is a multi-dimensional process. Although the educators may possess a high familiarity level regarding effective evaluating practices, yet they, in fact, lack the confidence required to actively implement those practices (Looney, Cumming, Kleij, Van Der \& Harris, 2017). However the reluctance of the kindergarten educators to use alternative assessment techniques is probably due to their limited knowledge on the ways of implementing them, as well as to the fact that there is a remarkable shortage on psychometric information and weighted assessment tools, along with the lack of relevant culture for the practical evaluation of toddlers (Eurydice, 2012). Within the Kindergarten, traditional assessment forms fail to work effectively since not solely the impact on the cognitive field is evaluated, but also there is an emphasis on the ways of achieving knowledge, the procedures involving creative work and the communicational skills of the children along with the 
cultivation of critical thinking, the undertaking of initiatives hence the acquisition of responsibility through collective work, the all-round development of the child in general, are pointed out.

Educators make use of various techniques either alone or in combination, not all of them, however, gain adoption in the same degree since, as it is manifested through our research, observation is more frequently implemented by both our educators' investigative groups. Similar are the findings of studies on which it is pointed out that in the context of a holistic approach to the children's daily responsiveness in the kindergarten class, observation seems to have been the prevailing means of assessment, given that it has been the dominant pedagogical culture frame regarding the fields of evaluation during the last two State Curricula for the Kindergarten on which observation has been revered as a most comprehensive, appropriate, effective and developmentally suitable form of evaluation (Manolitsis \& Economidis, 2013).

Future educators, as it was established by research, are highly knowledgeable on assessment issues and are competent towards alternative assessment techniques however they meet obstacles on practical implementation of such. It seems that the common belief of the existence of a significant gap between convictions and actualization is in fact true, subsequently there is a divergence between theoretical knowledge and practical realization (Wang, Elicker, McMullen, $\&$ Mao, 2008).

Some percentage of the sample reported difficulties during the implementation of the assessment, pointing shortage in time, large number of pupils in the kindergarten class as well as lack of infrastructure being the main problems. Such difficulties appear to be the components of imminently affecting the assessment process and have been pointed out as such, during previously conducted studies (Manolitsis \& Economidis, 2013).

We established that most of the participant educators consider mapping out the evolution of children in order their school readiness to be estimated for the children's transition to the next school level as a major purpose of assessment. A remarkable amount of recent studies brings about the assessment of school readiness level as a crucial indicator towards the children's transition to the next level, as well as towards determining their needs, interests and tendencies (Haskins, \& Barnett, 2010).

Hopeful teachers of pre-school education implemented diagnostic, formative as well as summative assessment for their teaching during their internship, all based on the knowledge they had acquired during their university studies, seeking thus to visualize the degree of evolution and progress of each child, rather than monitor comparative purposes. Kindergarten educators on the other hand, mostly opt for drawing upon information which originate from the results that occur at the end of an activity, in order to conduct their final evaluation. The effectiveness of an educator has, besides, been correlated to the degree at which evaluation is used for serving formative rather than comparative purposes (Creemers, \& Kyriakides, 2008).

Future kindergarten educators implemented evaluation not only on organized and free activities, but also on those of daily routine. The information that is utilized for evaluating toddlers should be gathered from the whole range of activities the children are involved with and as such, they become of uttermost value towards the determination of the child's readiness and abilities level (Nah Kwi-Ok and Kwak Jung-In, 2011).

Kindergarten teachers but no less students themselves implemented assessment throughout all the cognitive domains included within the kindergarten as it is clear that a child's progress relies on the cultivation and development of all their skills- socio-emotional, subtle and agile mobility skills, linguistic, cognitive, mathematic skills et al.- all of which are being promoted during pre-school age (Ziv, 2013).

Most of the kindergarten teachers taking part on the current research gave a positive response to the question regarding whether they wish to be reeducated on subjects that concern toddler evaluation. They clearly stated that as a first option they would desire such a reeducation were held under organized, institutionalized as well as systematic retraining policies. The vast majority of educators deem that the organization and actualization of retraining curricula destined for the professional evolution of the educators but also for an effective and practical implementation of the assessment under specific criteria and by specific means in order the quality of the offered educational service to be ameliorated, is definitely necessary (Christoforidou, Kyriakides, Antoniou, \& Creemers, 2014 · Baird, 2010).

\section{Conclusions}

Closing, the data of this study have pointed out a positive outlook towards the implementation of alternative assessment techniques for the kindergarten, on the future educators' side, however clearly indicated the difficulties regarding their practical actualization. On the other hand, teachers seem to be feeling quite inadequate in terms of retraining and updating on assessment issues, have a rather tentative disposition towards the real purpose of assessment and follow more traditional, stereotypical, so to say, pathways of evaluating the expected effects of 
teaching and learning. In completion of this investigative study, we suggest that on the side of the Official State, the perceived organizational support should be taken under consideration towards the provision of occupational development curricula which ought to be intensive, continuous and firmly attached to the practical implementation of the assessment. It is of crucial importance that the educators become familiarized with the alternative evaluation techniques on the purpose of difficulties and hinders to be overcome. Finally, it is necessary that the Curricula within the Greek Universities' Departments of Early Education should be reformed as well as enriched with autonomous courses that focus on educational assessment accompanied with the enhancement of implementation practices, so that the conditions of implementing genuine assessment techniques, as well as the development and promotion of a holistic educational model, are ascertained.

Funding: This research received no external funding.

Acknowledgments: This research did not receive any specific grant from funding agencies in the public, commercial, or not-for-profit sectors.

Conflicts of Interest: The authors report no conflict of interest.

\section{References}

Bagnato, S. (2009). Authentic Assessment for Early Childhood Intervention. Best practices. Guilford Press: New York.

Baird, J.-A. (2010). Beliefs and practice in teacher assessment. Assessment in Education: Principles, Policy \& Practice, 17(1), 1-5. https://doi.org/10.1080/09695940903562682

Charisis, A. (2006). Alternative forms of cognitive assessment and Cross Thematic Curriculum Framework (CCTCF/ А.Е.П.П.Е.). In Kakanas, K. Botsoglou, N. Haniotakis, \& E. Kavalari (Eds.), Assessment in Education: Pedagogical and didactical dimensions (pp. 283-290). Kyriakides bros: Thessaloniki, Greece.

Christoforidou, M., Kyriakides, L., Antoniou, P., \& Creemers. (2014). B.P.M. Searching for stages of teacher skills in assessment. Studies in Educational Evaluation, 40, 1-11 https://doi.org/10.1016/j.stueduc.2013.11.006

Constantinou, Ch., \& Constantinou, J. (2017). Assessment in Education, Evaluating the educational work, the educator and the pupil in terms of theory and action. Gutenberg: Athens, Greece.

Creemers, B. P. M., \& Kyriakides, L. (2008). The dynamics of educational effectiveness: A contribution to policy, practice and theory in contemporary schools. Routledge, London.

Doliopoulou, E. (2008). Kindergarten Educators' views on the implementation of the Kindergarten Teacher's Guide. Synchroni Ekpaidefsi, 153, 165-1820. Retrieved $20 \quad$ April 2019, from https://ejournals.lib.auth.gr/1105-3968/article/view/942/0

Doliopoulou, E., \& Gourgiotou, E. (2008). Assessment in pre-school education. Gutenberg: Athens, Greece.

Eurydice. (2004). Evaluation of Schools providing Compulsory Education in Europe. Retrieved 20 April 2019, from www.Eurydice.org

Eurydice. (2012). Key to data on Education in Europe. Brussels. Retrieved 20 April 2019, from https://eacea.ec.europa.eu/national-policies/eurydice/content/key-data-education-europe-2012_en

Gullo, D. (2005). Understanding assessment and evaluation in early childhood education. NY: Teachers College Press, New York.

Haskins, R., \& Barnett, W. S. (Eds.) (2010). Investing in young children: New directions in federal preschool and early childhood policy. DC: The Center on Children and Families and the National Institute for Early Education Research, Washington.

Institute of Education, Ministry of Education and Religions. (2013). Interdisciplinary Single Curriculum Framework for Kindergarten. Retrieved from http://www.pi-schools.gr

Irving, S., Harris, L., \& Peterson, E. (2011). 'One assessment doesn't serve all the purposes' or does it? New Zealand teachers de scribe assessment and feedback. Asia Pacific Education Review, 12(3), 413-426. https://doi.org/10.1007/s12564-011-9145-1

Linda- Darling Hammond. (2015). Teacher Assessment: A Methodological Proposal. Papazisis: Athens.

Looney, A., Cumming, J., Kleij, F. Van Der, \& Harris, K. (2017, May). Reconceptualising the role of teachers as assessors: teacher assessment identity. Assessment in Education: Principles, Policy \& Practice, 1-26. https://doi.org/10.1080/0969594X.2016.1268090 
Manolitsis, G., \& Economidis, V. (2013). Preparedness and practices of kindergarten teachers in Crete for the evaluation in the Preschool Education. In Education and Teacher Education in the World. Modern trends, problems and prospects. Proceedings of International Symposium, University of Crete Pedagogical Department of Primary Education, Rethymno, Crete, Greece, pp. 329-344.

McAfee, O., Leong, D., \& Bodrova, E. (2010). Basics of assessment within the pre-school education. Introduction Scientific Editing: M.Sakellariou- M. Konsolas. M. Plyta Trans. Papazisi Publications: Athens, Greece.

Nah, K-O., \& Kwak, J-I. (2011). Child Assessment in Early Childhood Education and Care Settings in South Korea. Asian Social Science, 7(6). https://doi.org/10.5539/ass.v7n6p66

Puckett, M. B., \& Diffily, D. (2003). Teaching young children. An introduction to the early childhood profession. Albany, NY: Delmar.

Wang, J., Elicker, J., McMullen, M., \& Mao, S. (2008). Chinese and American preschool teachers' beliefs about early childhood curriculum. Early Child Development and Care, 178(3), 227-249. https://doi.org/10.1080/03004430600722671

Wortham. S. C. (2015). Assessment in early childhood education (7th ed.). OH: Pearson Prentice Hall, Columbus.

Ziv, Y. (2013). Social information processing patterns, social skills, and school readiness in preschool children. Journal of Experimental Child Psychology, 114, 306-320. https://doi.org/10.1016/j.jecp.2012.08.009 